\title{
Application of Computer Technology in Human Resource Management and Social Security
}

\author{
Tianji $\mathrm{Li}^{1, *}$ and Lequn $\mathrm{Li}^{2}$ \\ ${ }^{1}$ Hunan Labor and Human Resources Vocation College, Changsha 410126, Hunan, China; ${ }^{2}$ Hunan Mass Media \\ Vocational Technical College, Changsha 410100, Hunan, China
}

\begin{abstract}
As the greatest production tool in twenty-first Century, computer technology has the non-substitute status in people's life. With the expansion of the Internet, the computer has a profound impact on modern life. Human resources management department actively introduce computer technology, to provide technical support for social security work. The wide application of computer in human resource management has greatly promoted the development of social security Since the reform and opening up, China has introduced the market competition system, greatly liberated and developed the productive forces.. With the development of social economy and technology, computer application technology has penetrated into every field of the society, which greatly facilitates people's production and life.. Government departments also actively use computer network system. This paper mainly talks about the application of computer in human resources and social security, and studies the effective way to improve the work efficiency of human resource and social security department.
\end{abstract}

Keywords: Computer technology, human resource management, social security.

1. THE NECESSITY OF APPLICATION OF COMPUTER TECHNOLOGY IN HUMAN RESOURCES AND SOCIAL SECURITY WORK

\subsection{The Requirements of the Times}

With the rapid development of economy, the proficiency of computer technology has become the standard to measure the talent, the efficiency of the direct relationship to the level of personal wages. Our country is in the application of computer technology in the human resource management is the requirement of building a modern society in the new era of the construction of science and technology.. Human resource information management is also fully reflected in politics government department people-oriented service concept, and promote the harmonious development of society.

\subsection{Requirements of the Information Age}

This century, the main task of our country is to accelerate the establishment of a socialist harmonious society [1]. The workload of the human resources and social security, complex, time consuming and need to staff, in the face of these problems, establish an information network came into being, and the realization of our government information requirements.

\subsection{Guarantee Working Efficiency}

Modern information technology for data processing, processing, storage and other fast, accurate, simple, and can soon be released to the general public. In the calls for "using the least amount of time, do most of the work of the efficient work environment, the establishment of human resources and social security information network, can continue to improve resource use structure, ensure the work efficiency.

\subsection{Stimulate Personal Potential}

To establish efficient and reliable information network, can promote the staff's enterprising spirit, continuous learning new knowledge, in order to adapt to the working environment of the information network, maximum limit to stimulate individual potential, optimize the organizational structure.

\subsection{Promoting the Construction of Independent Gov- ernment}

Use computer to collect, process information data, publish a message, let the public participate in, discuss government decision-making With the intelligent computer software, a public speech channel more, the government to make more in line with the needs of the public more scientific decision-making, truly people-oriented, promote the construction of a clean and honest administration [2].

\section{THE EXPLANATION OF THE PROBLEM}

\subsection{The Meaning of Information Technology}

Generalized information technology is using computer language, acquisition, storage, transmission, analysis, processing, the use of information, so that the information technology to achieve standardization; also can be understood by computer, network, broadcast and television, etc. all kinds of 
scientific method of graphic information such as audio and video processing, Technology and use of technology.

\subsection{Human Resources}

China has a lot of labor, which is in the working age, with the ability to work the people collectively referred to as human resources, they are the main force in the construction of the socialist market economy in China. Human resources management is essential, adequate human resources are helpful to the productivity and the entire social economy The development of.

\subsection{The Social Security}

Social security is an effective government mechanism for the government to solve the social risk between workers and members of society. Germany as the earliest country to establish labor security, it emphasizes the concept of social justice, while the concept of safety in the first place. The mainstream view is that: the employment of re-employment, the maintenance of workers' rights and interests [3], and social construction are social security work content. It highlights the responsibility of the state and the government is the main body to provide public services, assistance and other activities, to achieve the effective allocation of resources and mobility, to ensure social stability.

\section{THE HUMAN RESOURCES AND THE SOCIAL SECURITY INFORMATIONIZATION CONSTRUC- TION COUNTERMEASURE}

\subsection{Accelerate the Development of Software}

Computer software is the key to computer. At present, the software development of our country is still in the primary stage, but the human resources and the social security informationization construction urgently needs a suitable, can satisfy all kinds of business processing software system. Can make the majority of citizens and government human resources and social security departments to communicate highly, to ensure the high speed operation of human resources and social security departments.

\subsection{The Establishment of Employment Information Net- work and Social Security Resources Network}

For the society and all kinds of talents, find a good job is vital, and find work for the channel and not so much, so government has established an employment information network can to facilitate public understanding of the social recruitment information; establish social security network resources, let the public understand and accept the conditions of social security, social security system transparency, fair.

\subsection{Government Policies and Regulations Support}

The establishment of human resources and social security information network, the need for coordination of various departments, more need to support the government policies and regulations. The moral hazard of the social security of the traditional government mechanism is more than that, in addition, the financial pressure of the government pays the pension in advance. Therefore, the government departments should strictly participate in the social security personnel conditions; at the same time put an end to the false information on the information network publication. If you find, give severe criticism, the circumstances of severe punishment, in order to guarantee the authenticity and reliability of the information.

\subsection{Establish Synchronization Security Information Network}

Network is a highly open environment, employment information and social security involves to the self-interest of each worker and the insured, so in the establishment of human resources and social security information network, at the same time [4], we should establish synchronization network security system. Establish different authentication agencies, different levels of security, to confirm the identity of the visitor, to ensure that after the event can find the basis for processing.

\section{COMPUTER TECHNOLOGY INTEGRATION}

\subsection{Computer Application in Human Resources and So- cial Security}

\subsubsection{Computer Technology to Adjust the Structure of Human Resources Management}

The human resource management structure is divided into two parts, the internal management area and the external management area. The role of computer in the area of internal management embodied in between units, between members of the exchange, through the establishment of enterprise internal office network to ensure employees receive timely information and execute a command, while increasing the confidentiality of content delivery; the wide application of computer technology realized enterprise paperless office, reduce waste, save office expenses, reduce the operating costs of enterprises; informatization office staff to improve processing speed and ability of things [5], as a unit to reduce the employees, but also guarantee the achievement rise, increase the enterprise profit. External application is divided into two directions, that is, the face of the public and the face of other relevant departments. The external management region has increased the transparency of human resources work, is conducive to the enhancement of contact with the outside world, easy for human resources management to accept foreign suggestions and supervision.

\subsubsection{Provide Technical Support to the Establishment of Human Resources Database}

The computer database technology can effectively deal with the huge data information in human resource management, and it has changed the previous working condition. Human resource data before the use of artificial statistical methods, a lot of time and energy, and the performance is not obvious. Computer not only have large data processing and storage capabilities, but also according to different standard classification and statistical results is more accurate [6], for the relevant personnel to provide convenience to the working conditions. The computer technology has greatly improved people's working efficiency, meeting the needs of social development. 


\subsection{Improve the Application of Computer Technology}

\subsubsection{Increasing Software Development Efforts}

The professional human resources office software can not only improve the work efficiency, guarantee the talent information and the market condition to get the prompt renewal, also is advantageous for the related government department secrecy work development. The development of computer software is an important method to improve the social security. At present, the human resources and social security informationization in China are still lack [7], and need excellent software assistant to establish a complete and efficient information network service platform. The perfect human resource information system can help the government supervise the government departments, and make the social security work more clean and improve the efficiency of the human resources department.

\subsubsection{Government Support}

The government should introduce policies and regulations, eliminate the interference factor outside the outside, ensure the human resources department work smoothly. With the increase of the transparency of the work, we should synchronize the security network system, pay attention to protect the legitimate rights and interests of workers, and provide reliable social security for people.. The government should adjust the enthusiasm of the departments to mobilize the enthusiasm of the departments to gather the strength of all sectors of society, and establish the social security information system of real and standard.

\subsection{Human Resource Management System Needs}

\subsubsection{Overall Demand Target}

The use of advanced computer network technology, and database and development platform in the process, the existing software, and combined with related hardware settings, continue to build to implement the open architecture, easy to expand, easy maintenance, with good man-machine interface of the human resources management system, so as to help the enterprise to realize the transfer of personnel, salary adjustment, personnel automatic cutting, promote computer system play the efficient performance.

\subsubsection{Data Needs}

(1) To ensure data input is the basic requirement for data processing, if the input error will cause the error or invalid system output, so that the whole system can't play a role. Manual input is the main source of data input. In fact, the main way is to use the system interface to maintain the system of fault tolerance, but also to the operator to start professional training system. The input of data is usually large in the system, which requires the design of the system must have a strong processing ability, to ensure that the speed of processing data.

(2) The security of data operation this paper, the design of the system is mainly to serve the enterprise human resources management work, and not all human resource managers are able to control the system, only the provisions of personnel to the data add, delete, change, check operation, did not get authorized personnel can't enter the system. In the process of information inquiry, we should strictly follow the definition of authority, and carry out strict qualification to the information collection, so as to make the information data have a high security performance.

\subsection{Design of Human Resource Management System}

\subsubsection{Architecture}

Mutual said, referring to the three layer $\mathrm{C} / \mathrm{S}$ structure model design, the whole system planning into the client application data layer, function layer three aspects: customer application layer, the installation position of the branch, branch, room or department of human resources management client; data layer refers to the SQL Server database server, it is a variety of data storage location, the installation position in the human resources management center server; function layer is used in various kinds of logical, algebraic operation, can make the application system to obtain accurate results, the installation position can be individually placed on a server, convenient processing client connection. The functional layer includes seven subsystems: basic information management, wage information management, vacation information management, system maintenance, file information management, attendance information management, query statistics. The implementation of the system is accomplished by several subsystems.

\subsubsection{Design of System Database}

\section{(1) Data classification stored}

The staff basic information material; the personnel records information; the personnel attendance $i$; the personnel leave; the personnel wages information; the information maintains the information material.

\section{(2) Software control flow design}

Add operation: system adding a new record to the database and the information table is modified; queries: query information of the user to input the corresponding system in accordance with the conditions to the query in the database search, then the query results input; modified operation: due to the information itself will continue to change, it is necessary to to amend the information processing. After the query operation is executed, the corresponding data in the operating system is modified, and the operation is performed after the query is executed, and some of the system is not used and the record is removed directly.

\subsection{System Establishment Background}

(1) CPU: IntelPentium 166MHz: (2) operating system: MicrosoftW indows $98 / \mathrm{me} / \mathrm{XP} / 2000$ (3) monitor: VGA or higher resolution monitor Microsoft Windows. (4) memory: $65 \mathrm{MB}$ memory above.

\section{SYSTEM DESIGN IDEAS}

\subsection{Design Ideas}

In the field of human resource management, computer is not just a tool for keeping data, it can also show the problems reflected by the deep data mining. First, we need to data mining human resources, select the user data, and then 


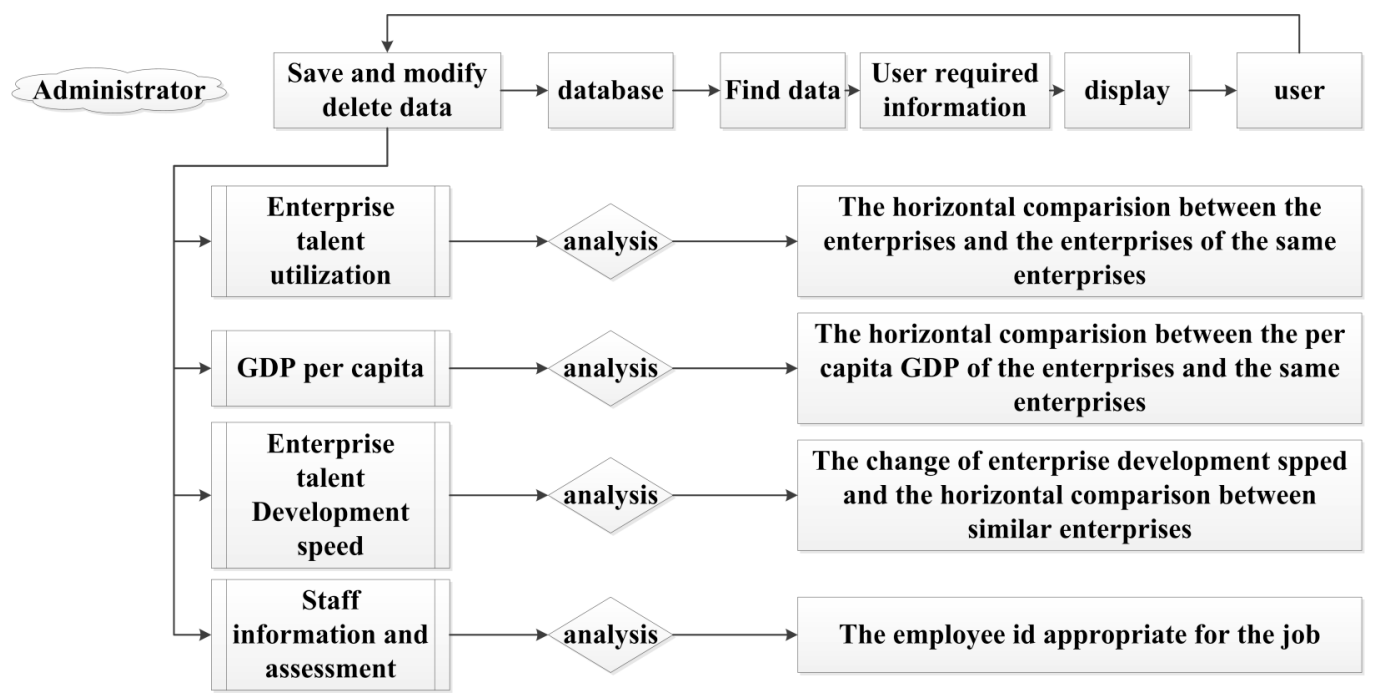

Fig. (1). System data flow chart.

generate intuitive graphics based on these data, such as histogram, graph and pie chart, etc.. Subsequently the data and graph analysis, we found the incongruous unreasonable allocation of human resources, and according to all aspects of enterprise, summarizes solutions, provide a reference for the user.

\subsection{System Development Tools}

System to ensure the completion of the basic operation of the premise, you can also meet the following requirements: (1) the page is stable version of the browser and set. The database is reasonable in structure, easy to maintain and expand, reduce redundant data, improve the independence of programs and data.

\subsection{Demand Analysis}

\subsubsection{Data Needs}

The computer assistant enterprise human resources management and development system needs to collect the following data:

The total number of enterprises in the post workers, age structure, professional title structure, cultural level structure, annual production value of enterprises, high, medium and low-level technical personnel number, number of innovative talents, new products launched time, whether successful, employee personal information and evaluation information, and other enterprises of the same type of indicators. The utilization of human resources is an important indicator of whether the enterprise human mechanism is reasonable or not.. Special concern is the utilization of advanced technology, it is the embodiment of human resources of enterprise. Through the senior technical personnel in a certain period of time per capital to create a value and the value of the enterprise can create a value comparison, can reflect the advanced level of enterprise advanced technology talents. If compared with the value of the same type of high tech talents per person, it will reflect whether the enterprise human resources in the same type of enterprise is competitive. Innovative talent share also need to draw attention. The development of an enterprise not only to Gong live in your own natural advantages, but also to expand the advantages of the new, which requires the contribution of innovative talents. The length of the new product launch cycle, the success of the success and other factors are the measure of the use of innovative talents is reasonable standards. Enterprise managers also need to assess the ability of employees regularly, in order to assess whether the employee is suitable for the present job, or in this post, whether it can play its maximum effectiveness. Enterprise's per capital GDP is on-the-job workers per capital created GDP, and enterprises throughout the year production total value, and the number of workers in the post are related, the statistical index is also a measure of the organizational structure of enterprise human resources is reasonable standard of. Human resource management and development of enterprise need to recognize the flow and development of talents, pay attention to the development speed of enterprise talents, and promote the optimization of talents.

\subsubsection{Data Flow Structure}

According to the computer assistant enterprise human resources management and development system data flow and processing, design the system data flow Fig. (1). The administrator of the database operations, the user requests the application, the system according to user needs to find the database, and through the browser output results. In the system to find the data, it will be analyzed, and some conclusions are drawn for the user to provide a reference.

\subsubsection{Function Module Chart}

According to actual needs, the function of the program is modular. According to the system structure, it can be divided into three modules: information query, statistical analysis and administrator management.. Information inquiry is based on the user's needs to complete the database query operation; statistical analysis is to achieve graphics generation operation, and the data from the analysis, the conclusion is that the administrator management module is mainly to realize the database, modify, delete and backup operation. 


\subsection{The Main Functions of the System Technology}

\subsubsection{Online Information Query}

Online query is an important function of the system.. Each index has a year, departments and other query terms for the user to choose. The employee information query module can not only individual query by name, Department, etc. It can also through the age range information fuzzy query, can also use a complex query. Through

The link between the pages can easily find the information you need. Data as well as the online publication of the graphics can be used to query and manage information through the Internet anytime and anywhere.

\subsubsection{Programming graphics Display}

In the analysis of human resources in the enterprise need to generate a variety of graphics based on data, such as histogram, graph or pie chart, etc. Data changes, graphics also changed. Implementation method is as follows: first the graphical 58 Shenyang Institute of Aeronautical Engineering Journal of rendering algorithm written JavaBean, then call the database in JSP pages, the database drawing required data out to write the array, graphics rendering call JavaBean, *. JPG format pictures and in the page can show after drawing all kinds of graphics. Sometimes, from the database to calculate the data after the need to be calculated before writing to the array, then call JavaBean to draw graphics.

\subsubsection{Analysis Summary}

By calculating the difference of numerical indicators of a certain period of time within the same time interval to determine whether the normal variation, in the analysis enterprise high technical talents in 2004 per capital created value as a business in the past five years talent utilization rate of annual statistics on their own judgment and other types of enterprises with same indicators to compare the position is reasonable, and to set a reasonable value. According to the enterprise human resources and unreasonable values, find the database and match the final output solution.

\subsubsection{Data Management}

Administrator management module to achieve data management functions. Ordinary users only have the right to query, and administrators have the right to operate on the database, which improves the security of the data. In the data add module, the system also realized batch function, that is, once can add 5 or more records, reducing the workload of the administrator input data.

\subsubsection{Material Processing}

A good system not only to have the perfect function, but also have a beautiful practical interface, and the interface is largely determined by the material processing. The fine picture is important, but the size is also the factor that should be considered, IF G and JPEG is the form of the picture usually used on the web. Using to shop Photo produce a chart the film is very good. Flash animation not only can bring dyna- mic aesthetic feeling to the page, but also is a good way to attract the user's sight.

\section{CONCLUSION}

The society should correctly deal with the human resources and social security in the social development, and actively maintain the healthy and sustainable development of the social security system.. Human resources department should increase the ability to operate the staff in the Department of computer training, to ensure a good momentum of development of human resources information, to further expand the business coverage, so that the computer technology play a greater function in the human resource system of guidance, inspection and supervision.

The relevant government departments to highly aware of human resources and social security in the social development in the increasingly prominent and important role, and to establish the necessity of human resources and social security information network. According to the development of human resources and social security requirements, the real information construction of the work schedule, comprehensively promote the needs of the service to the public, service workers. The informationization construction achievement good to play its due role, the human resources and social security and network effectively integrate, will continue its full content, enlarge the coverage and play a role in the guidance, supervision and inspection of all aspects. Attaches great importance to the authenticity and safety of information, strengthen safety management, improve the legal awareness, and ensure the information system runs efficiently and orderly.

\section{CONFLICT OF INTEREST}

The authors confirm that this article content has no conflict of interest.

\section{ACKNOWLEDGEMENTS}

This work is supported by the Key Project of Guangxi Social Sciences, China (No. gxsk201424), the Education Science fund of the Education Department of Guangxi, China (No.2014JGA268), and Guangxi Office for Education Sciences Planning, China (No.2013C108).

\section{REFERENCES}

[1] Du Xiaojun, Geng Junchen, Wu Qiuhong, Hebei private enterprise human resources management information research. cooperative economy and technology, 2011.

[2] Wang Yajun, the problem and Countermeasure of university student employment service informationization. scientific and technological information Development and economy, 2010.

[3] Yang Hui, Ouyang. Information on the construction of African social security work plan in Beijing city. Journal of the Institute of labor management and management, 2003

[4] Chang Yongbin, the information construction of human resources and social security Set up to explore the. financial sector, 2012, (4): 56-63.

[5] Li Aiju. Problems and problems during the application of computer. The application of the computer optical disc software,2012,(22): 69-71. 
[6] Chang Yongbin, the information construction of human resources and social security Set up to explore the financial sector, 2012, (4): 56-63.
[7] Li Aiju. Problems and problems during the application of computer The application of the [J]. computer optical disc software,2012,(22):69-71.

(C) Li and Li; Licensee Bentham Open.

This is an open access article licensed under the terms of the (https://creativecommons.org/licenses/by/4.0/legalcode), which permits unrestricted, noncommercial use, distribution and reproduction in any medium, provided the work is properly cited. 